\title{
Study of the Diversity of Nematodes in Vegetable Crops in the Koulikoro Region (Mali)
}

Boubacar Kola Touré (Corresponding Author)

Faculty of Science and Technology USTT Bamako Mali; BP 3206 Bamako, Mali Email: boubakola@gmail.com

\section{Souleymane Koné}

Faculty of Science and Technology USTT Bamako Mali; BP 3206 Bamako, Mali

\author{
Binta Diallo \\ Institute of Rural Economy Bamako, Mali
}

\section{Etienne Guindo}

Institute of Rural Economy Bamako, Mali

\section{Mohamed Maïga}

Faculty of Science and Technology USTT Bamako Mali; BP 3206 Bamako, Mali

\author{
Article History \\ Received: 8 December, 2021 \\ Revised: 20 January, 2022 \\ Accepted: 2 February, 2022 \\ Published: 6 February, 2022 \\ Copyright (C) 2022 ARPG \& \\ Author \\ This work is licensed under \\ the Creative Commons \\ Attribution International

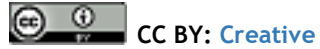 \\ Commons Attribution License \\ 4.0
}

\begin{abstract}
The market gardening sector is confronted with numerous constraints which weaken and hinder its development. Among these constraints is the importance of plant parasitic nematodes. For a sustainable management of these worms, a diagnostic evaluation was carried out in two permanent market gardening of Sébéninkoro (Kati) and Koulikoro town in order to determine their diversity. 54 soil samples of $500 \mathrm{~g}$ were taken from 3 plots, ie 27 samples per site. Analysis of these samples revealed the presence of 8 genera of nematodes. Among these nematodes there are nematodes of the genus Meloidogyne very harmful to crops and Tylenchorhynchus. They are common and abundant throughout both sites.

Keywords: Market gardening; Phytoparasitic nematodes; Diagnostic; Crops; Koulikoro.
\end{abstract}

\section{Introduction}

In Mali, market gardening occupies a prominent place among irrigated crops for several reasons. Among these reasons is their important contribution to food security, and also the increase in the monetary income of actors [1]. In Mali, revenue directly linked to this activity is estimated at CFAF 27 billion [2]. Vegetable production in Mali has increased significantly in recent years to reach a value of 1900173 tonnes over an area of 173110 ha [3]. According to the same statistics in terms of production, shallot is the most important crop with 401.285 tonnes. Next comes okra 254545 tonnes and tomato 175577 tonnes.

The World Health Organization (WHO) recommends consuming at least 400g of vegetables per day per capita, or five $80 \mathrm{~g}$ servings to take full advantage of their beneficial effects on health and nutrition [4]. In Mali consumption is estimated at $103 \mathrm{~kg}$ per person per year [5]. According to the planning and statistics unit of the rural development sector [6], the city of Bamako alone consumes around 22932 tonnes of vegetables per year. Onions and tomatoes are the most consumed with $34 \%$ and $25.5 \%$ respectively. Next come okra (12.5\%) and cabbage (9\%).

Yield losses caused by plant parasitic nematodes are estimated at $14.6 \%$ in tropical countries and $8.8 \%$ in developed countries [7]. Globally, this drop in yield is of the order of 12 to 20\% [8]. In terms of money, the related crop losses were estimated at 80 to 150 billion US dollars per year [9]. In Mali, nematological analyzes have shown that these nematodes pose serious problems on the malian market gardening sites visited in Bamako and Segou [10]. The most sensitive crops are Solanaceae (tomatoes, eggplant, potato), Cucurbitaceae (melon, cucumber), Legumes (beans), Umbelliferae (carrot, celery, etc.), Compositae (lettuce).

Despite the important role that market gardening plays in production, economic growth and food security, the sector remains subject to constraints that weaken and hinder its development.

Among these constraints, we can cite insect pests and especially nematodes. The objective of this study is to determine the diversity of parasitic nematodes associated with vegetable crops in the Koulikoro region.

\section{Materials and Methods}

\subsection{Study Sites}

Two permanent market gardening sites in the Koulikoro region (Koulikoro town and Sébéninkoro) were chosen for the collection of soil samples (Table 1). The samples were taken using a systematic method using a trowel. 
Journal of Agriculture and Crops

Table-1. Location of study sites

\begin{tabular}{l|l|l}
\hline \multicolumn{2}{l}{ Market gardening sites } & Geographical coordinates \\
\hline \multirow{2}{*}{ Koulikoro region } & Sébéninkoro (Kati) & $12^{\circ} 31^{\prime} 419 \mathrm{~N} ; 08^{\circ} 04^{\prime} 921 \mathrm{~W}$ \\
\cline { 2 - 3 } & Koulikoro town & $12^{\circ} 39^{\prime} 721 \mathrm{~N} ; 07^{\circ} 56^{\prime} 726 \mathrm{~W}$ \\
\hline
\end{tabular}

\subsection{Plant material}

Several vegetable crops that are exploited on these market garden sites have been selected for soil sampling: tomato, eggplant, lettuce and cabbage.

\subsection{Nematological Data}

\subsubsection{Sampling}

The samples were collected in the rhizosphere of vegetable crops along the two diagonals and two medians of the plots. The sample was taken during the off-season in February that is to say towards the end of the cold season by means of a trowel, at a depth of $25 \mathrm{~cm}$.

Twenty-seven silty-sandy soil samples per crop plot, ie 54 soil samples of $500 \mathrm{~g}$, were taken from 3 plots. These soils are characterized by their light, airy and permeable nature, therefore favorable to the development of nematodes. Each sample is placed in plastic bags labeled with the name of the site, a sample number, the name of the crop, all well sealed with a thread. The samples were then collected in a cooler and transported to the lab for extraction.

\subsubsection{Extraction of Nematodes}

In the laboratory, a sub-sample of $100 \mathrm{~cm}^{3}$ is taken from each of the samples from the rhizosphere of the cultures to be analyzed. The remaining soil is kept moist for analysis in the event of accidents. The soil sub-sample is well homogenized by hand and cleared of all large debris. It then passed through a $2 \mathrm{~mm}$ mesh sieve before proceeding to nematology analysis.

To extract the nematodes we used the modified Baermann technique and a series of three sieves of $150 \mu \mathrm{m}, 70$ $\mu \mathrm{m}$ and $38 \mu \mathrm{m}$. Each sample was placed on a "kleenex" type paper, then placed on a PVC sieve with a $1 \mathrm{~mm}$ mesh. The whole thing is placed on a plate, water is then added to moisten it completely. 48 hours later, all of the water in the container is passed through the sieves so as to maintain a suspension of about $25 \mathrm{ml}$. A $5 \mathrm{ml}$ aliquot solution of this suspension is observed under a microscope at 40x magnification. The nematodes were fixed by immersion in a boiling solution of FA composed of $10 \mathrm{ml}$ formalin; glacial acetic acid $1 \mathrm{ml}$; distilled water 89 ml. The nematode count was done using a stereoscope at 40x magnification.

\subsubsection{Identification of Parasitic Nematodes}

The generic determination of phytoparasitic nematodes was made using a determination key [11] and the discriminating morphological characters reported by Mateille and Tavoillot [12]. The count of nematodes was carried out with an inverted pole microscope of the PARALUX type at 40X magnification.

\subsubsection{Data Analyses}

From a suspension adjusted to $25 \mathrm{ml}(\mathrm{V})$, take a $5 \mathrm{ml}$ aliquot (v) which is placed in a counting box with a grid bottom for counting. After enumeration, the population size was expressed in number of nematodes / dm 3 of soil ( $\mathrm{N}$ / dm3) according to the formula:

The importance of each nematode genus was determined by calculating the average density per site, frequency of occurrence and relative abundance. An analysis of variance was performed in order to compare the means by site and by gender.

The frequency of occurrence (F) of a species is the ratio expressed as a percentage of the number of samples where this species is noted to the total number of samples taken:

$\mathbf{F}=$ frequency of occurrence of the species.

$\mathbf{P n}=$ total number of samples containing the species in question.

$\mathbf{P t}=$ the total number of samples taken.

According to Dajoz [13] we distinguish: constant species ( $\mathrm{F} \geq 50 \%)$, accessory species $(25 \%<\mathrm{F}<50 \%)$, accidental species $(\mathrm{F} \leq 25 \%)$. The relative abundance $(\mathrm{A})$ of a species corresponds to the ratio of the number of individuals of the same species to the total number of individuals, all species combined.

\section{Results}

The nematodes encountered: 54 samples from the two permanent market gardening sites were analyzed and the phytoparasitic nematodes extracted. 8 genera have been identified (Table 2), they are: Pratylenchus, Meloidogyne, Scutellonema, Tylenchorhynchus, Heterodera, Helicotylenchus, Criconemella, Hemicycliophora. The frequency of occurrence, abundance and density provide information on the biology and ecology of the nematofauna found. Four of them are ectoparasites (Criconemella, Scutellonema, Tylenchorhynchus, and Helicotylenchus). Endoparasites are distributed in sedentary (Meloidogyne), migratory (Pratylenchus). 
Journal of Agriculture and Crops

Table-2. The phytoparasitic nematodes identified

\begin{tabular}{l|l}
\hline Families & Genus \\
\hline Heteroderidae & Meloidogyne; Heterodera \\
\hline Belonolaimidae & Tylenchorhynchus ; Helicotylenchus \\
\hline Hoplolaimidae & Scutellonema \\
\hline Pratylenchidae & Pratylenchus \\
\hline Criconematidae & Criconemella \\
\hline Hemicycliophoridae & Hemicycliophora \\
\hline
\end{tabular}

\subsection{Importance of Nematodes}

Total nematode densities per kg of soil varied from site to site. Analysis of the results shows a variation of 790 nematodes per $\mathrm{kg}$ of soil and 878 nematodes per $\mathrm{kg}$ of soil respectively in Sébéninkoro and Koulikoro (Figure 1). Statistical analysis of the data shows that there is no significant difference between these densities (Anova, $\mathrm{P}=0.76$ ). Regarding generic densities, a variation was noted. The largest outbreaks were noted for Meloidogyne in Sébéninkoro and Tylenchorhynchus in Koulikoro, respectively 490 and 199 individuals per kg of soil. Statistical analysis of generic densities shows that there is no significant difference between the different genera $($ Anova, $\mathrm{P}=$ $0.54)$.

Table-3. Frequency of occurrence, Abundance and densities of nematodes encountered

\begin{tabular}{|c|c|c|c|c|c|c|c|c|}
\hline \multirow{2}{*}{$\begin{array}{l}\text { Genera of } \\
\text { nematodes }\end{array}$} & \multicolumn{3}{|c|}{ Sébéninkoro } & \multicolumn{3}{|c|}{ Koulikoro } & \multirow{2}{*}{$\begin{array}{l}\text { Means } \\
\text { F\% }\end{array}$} & \multirow[b]{2}{*}{ Types F\% } \\
\hline & F\% & A\% & D & F\% & A\% & D & & \\
\hline Criconemella & 33 & 1 & 7 & 50 & 18 & 155 & 83 & constante \\
\hline Meloidogyne & 100 & 62 & 490 & 100 & 18 & 152 & 100 & constante \\
\hline Tylenchorhynchus & 100 & 25 & 200 & 100 & 23 & 199 & 100 & constante \\
\hline Heterodera & 100 & 8 & 67 & 88 & 18 & 161 & 94 & constante \\
\hline Pratylenchus & 100 & 3 & 23 & 100 & 6 & 55 & 100 & constante \\
\hline Scutellonema & 0 & 0 & 0 & 88 & 8 & 69 & 44 & Accessoire \\
\hline Helicotylenchus & 0 & 0 & 0 & 33 & 5 & 44 & 17 & accidentelle \\
\hline Hemicycliophora & 33 & 0 & 3 & 50 & 5 & 45 & 42 & Accessoire \\
\hline
\end{tabular}

Legend: F\%: frequencies of occurrence, A\%: relative abundances, D: average densities over $1 \mathrm{~kg}$ of soil.

\subsection{Structure of Nematode Communities}

Eight genera of phytoparasitic nematodes were identified on all two market gardening sites, including 6 in Sébéninkoro and 8 in Koulikoro. These nematodes are distributed among five families of the order Tylenchida.

The frequency of occurrence and relative abundance allowed us to analyze stand structure. The results obtained showed that 6 and 8 genera were found respectively in Sébéninkoro and Koulikoro (Table 3). Among these genera 5 are constant with a frequency of occurrence greater than 50\%. These are: Criconemella, Meloidogyne, Tylenchorhynchus, Heterodera, and Pratylenchus. 2 are accessory: Scutellonema and Hemicycliophora. The genus Helicotylenchus is the only one that is of the accidental type.

In Sebéninkoro, nematodes of the genus Meloidogyne present an abundance of $62.03 \%$ with an average density of 490 individuals per $\mathrm{kg}$ of soil. On the other hand in Koulikoro the genus Tylenchorhynchus is less abundant with $22.61 \%$ and a higher density of 199 nematodes per $\mathrm{kg}$ of soil (Table 3 ).

\section{Discussions}

This study provides information on the diversity and abundance of nematodes associated with vegetable crops in the Koulikoro region. Of the 8 genera encountered Meloidogyne and Tylenchorhynchus are the densest. Studies in other countries have revealed the presence of several genera of plant parasitic nematodes associated with vegetable crops that reduce yield by causing economically significant losses. In Niger, research on nematodes associated with Solanaceae shows similar results [14].

On the other hand, in Morocco, such studies have revealed a greater diversity. There, 12 genera were found [15]. Root-knot nematodes of the genus Meloidogyne and the genus Tylenchorhynchus were detected in $100 \%$ of the sites surveyed. All these authors are unanimous that Meloidogyne constitutes the most dangerous genus for vegetable crops. They can cause losses of up to $60 \%$ of tomato production [14].

The structure of the nematode population was analyzed from the frequency of occurrence and relative abundance. Thus 5 genera were reported on all two sites with a frequency of more than $50 \%$.

Two have been described as incidental, meaning that their frequency of occurrence is between $25 \%$ and $50 \%$. Only the genus Helicotylenchus is considered accidental with F> 25\%. This importance of the populations of Meloidogyne, Tylenchorhynchus; Criconemella, Heterodera, and Pratylenchus follows the permanent cultivation practice and the dominance of Solanaceae such as tomato, pepper, eggplant. The results found in Burkina show that this variation in distribution could be partly due to the type of soil [16]. 


\section{Conclusion}

The results obtained from this study confirm that there is a significant diversity of parasitic nematodes on crops. These results confirm that the nematodes of the genus Meloidogyne and Tylenchorhynchus are the most frequent on vegetable crops in the region. The 8 genera identified in this study seem to be the most abundant and the most common on crops. They are characterized by a very wide host range which includes vegetable crops, cereals and legumes.

Regarding ectoparasitic nematodes, the most important are Tylenchorhynchus and Helicotylenchus. These data provide useful information to guide prevention and control programs against these pests of vegetable crops in Mali.

\section{References}

[1] Touré, B. K., 2017. Les nématodes des cultures maraîchères: Dynamique saisonnière des peuplements et détermination des espèces de Meloidogyne dans la zone péri-urbaine de Bamako. Thèse de Doctorat. Université des Sciences des Techniques et des Technologies de Bamako. Faculté des Sciences et des Techniques, p. 170.

[2] Drabo, A., 2017. Contribution des cultures maraîchères (Echalote et pomme de terre aux revenus des exploitations agricoles dans la zone de l'Office du Niger : Cas de la zone agricole de Niono. Mémoire Master 2. Université Paris Sorbonne.

[3] Ministère de l'Agriculture du Mali, 2018. "Statistiques de la direction nationale de l'agriculture sur la production des cultures maraîchères. Aout 2018. 09."

[4] FAO, 2021. Fruits et légumes - éléments essentiels de ton alimentation. Année internationale des fruits et des légumes, 2021 Note d'information. Rome.

[5] Projet d'appui au suivi des ODD en Afrique SODDA, 2021. "Analyse des bilans alimentaire du Mali sur la période 2015-2018. Rapport définitif 2021." p. 54.

[6] Ministère de l'Agriculture du Mali, 2016. "Annuaire de statistique 2015 du secteur de développement rurale." p. 133.

[7] Mitiku, M., 2018. "Plant-parasitic nematodes and their management." A Review. Agrculturali Research and Technology: Open Access Journal, vol. 16, p. 555980.

[8] Dubois, E., 2019. Les nématodes parasites des plantes : description, moyens de lutte et impact sur la faim dans le monde. Thèse de Doctorat. Faculté de Pharmacie, Université de Lille. Année universitaire 20182019, p. 272.

[9] Coyne, D. L., Cordata, L., Dalzell, J. J., Claudius-Cole, A. O., Haukeland, S., Luambano, N., and Talwana, H., 2018. "Plant-parasitic nematodes and food security in sub-Saharian Africa." Annu. Rev. Phytopathol, vol. 56, pp. 381-403.

[10] Touré, B. K., 2017. Les nématodes des cultures maraîchères : Dynamique saisonnière des peuplements et détermination des espèces de Meloidogyne dans la zone péri-urbaine de Bamako. Thèse de Doctorat. Université des Sciences des Techniques et des Technologies de Bamako. Faculté des Sciences et des Techniques, p. 170.

[11] Mai, W. F. and Mullin, P. G., 1996. Plant-parasitic nematodes: a pictorial key to genera. New York, USA: Cornell University Press. p. 277.

[12] Mateille, T. and Tavoillot, J., 2012 "Identifier les maladies et les ravageurs. IRD. Montpellier. Site : ephytia. INRA.fr. Consulté le 8 Février 2016 à 11 heures."

[13] Dajoz, R., 1985. Précis d'écologie. 5e édition ed. Paris, ISBN, 505: Bordas.

[14] Haougui, A., Basso, A., and Mossi, M. I., 2017. Les nématodes parasites du Moringa dans la zone périurbaine de Niamey. Institut National de la Recherche Agronomique du Niger, p. 10.

[15] Krif, G., Mokrini, F., El Aissami, A., Laasli, S.-E., Imren, M., Özer, G., Paulitz, T., Lahlali, R., and Dababat, A. A., 2020. "Diversity and management strategies of plant parasitic nematodes in moroccan organic farming and their relationship with soil physico-chemical properties. Agriculture 2020, 10, 447." p. 26. Available: www.mdpi.com/journal/agriculture

[16] Konaté, A. Y., Ouédraogo, S. L., and Koné, D., 2019 "Etude faunistique des nématodes phytoparasites de l'oignon (Allium cepae L., Alliaceae) au Burkina Faso." Int. J. Biol. Chem. Sci., vol. 13, pp. 1388-1395. Available: https://dx.doi.org/10.4314/ijbcs.v13i3.14 
Figure-1. Distribution of plant parasitic nematodes by site

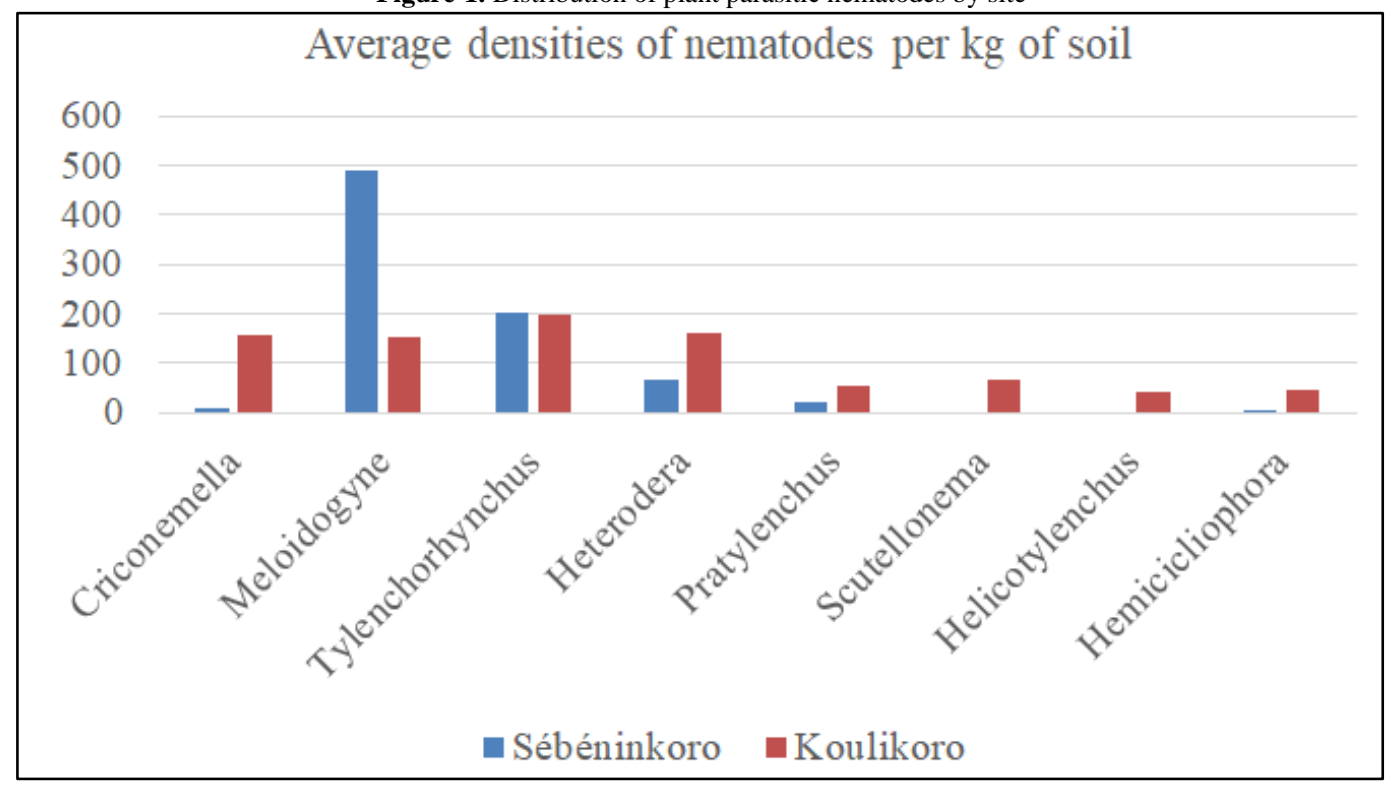

